\title{
Socio-Psychological Impacts of Terminal Illness on Patients and their Spousal Relationship
}

I. Ullah (lhsan Ullah) ${ }^{1}$, A. Naz (Arab Naz) ${ }^{2}$

${ }^{1}$ PhD Scholar, Department of Sociology, University of Malakand, PK.

2 Dean Faculty of Social Sciences, University of Malakand, PK.

\section{E-mail address:}

arab_naz@yahoo.com

\section{Reprint address:}

Arab Naz

University of Malakand

Faculty of Social Sciences

Pakistan

Source: Clinical Social Work and Health Intervention

Volume: 12

Issue: 4

Pages: $41-48$

Cited references: 17

\section{Reviewers:}

Steve Szydlowski

University of Scranton school of education, USA

Pawel S. Czarnecki

Rector of the Warsaw Management University, PL

\section{Keywords:}

Terminal Illness. Pakhtun Society. Socio-psychological. Impacts. Depression. Spousal Relationship. Life Style.

\section{Publisher:}

International Society of Applied Preventive Medicine i-gap

CSWHI 2021; 12(4): 41 - 48; DOI: 10.22359/cswhi_12_4_05 CC Clinical Social Work and Health Intervention

\section{Abstract:}

This phenomenological study was conducted to explore the impacts of terminal illness on patients and familial relationships of couples in Pakhtun society. 36 terminally ill patients selected purposively were interviewed separately ( 24 male \& 12 female patients) by the way of open-ended questions. Numerous themes were extracted following verbatim transcripts. All the participants explained the impacts of terminal illness on their social lives and the positive and negative aspects of their spousal relationship. Depression, anger and desperation were apparent in the terminal patients. Similarly bitterness, guilt, persistent sadness and loss were common in the patients and alternatively in their partners as explained by the patients.

This research highlights a distinct viewpoint on the damaging influences which terminal illness can have on the marital relationship. However it also recommends how to deal the situation 
in a positive manner by making adjustments required by the concerned disease. The findings indicate that social scientists need to confess and reply to the incredible psycho-social impacts that serious illnesses and related medical procedures can have on the patients and their families even in this modern era of advance technology. Advance social and psychotherapeutic techniques and socio-psychological support of partners can assist such patients to live with a positive life style till the end.

\section{Background of the Study}

Terminal illness is a life limiting condition which carries a high risk of mortality with irreversible decline and expected survival in terms of months or less (Hui et al, 2014). However, technological advancement in the field of medicine has helped people to live with terminal illness for a prolonged time hence such patients need to adapt themselves with multiple physical and social complications as the disease process moves on (Altschuler, 1997). Similarly it also affects the spouse of the patient and the relationship between the two as explained by Sohlman (2004) that various aspects of the relationship like: communication; values; beliefs; socioeconomic relations are heavily influenced. Healthier relationship between partners which has developed before the commencement of the severity of the illness is affected up to a larger extent as one partner become dependent on the other socially and economically. This phenomenological research is first of its nature which is aimed at investigating the Pakhtun community for socio-psychological impacts of terminal illness on patients as well as on their spousal relations.

\section{Statement of the Problem}

The intended objective of this study was to explore the impact of terminal illness on the patients and their spousal relationships. The reason this study is considerable is that there is a deficiency of knowledge about the phenomenological influence of mortal disease on the patients and spousal relationships with psychosocial consequences. We assumed that the psychosocial assistance from the spouse would facilitate and minimize the severity of the terminal illness although the disease would have substantial physical impacts on the patient.

\section{Objective of the Study}

The study is based solely on the aim to assess the socio-psychological impacts of terminal illness on the patients and their spousal relationships

\section{Literature Review}

Earlier than 1960, the only option for terminally ill patients was a quicker and peaceful death as due to inadequate medical technology prolonging of life was not possible. Belding Scribner, an influential nephrologist clarified that "as long as the struggle for survival was the main issue, emotional and social problems were ignored". This statement led researchers to focus patients for social, psychological and spiritual aspects of terminal illness in their studies (Levy 1996). 64 terminally ill patients were studied by Allen (2003); different stressors were identified and ranked. Fatigue, physical limitations and social maladjustment were recognized as the 3 uppermost stressors. These 3 were followed by psychosocial stressors like an isolated social life and uncertain future. Among the terminally ill population, anxiety and depression are well documented phenomena (Burton et al. 2004) however, due to methodological issues the authentic prevalence is not clear.

A great deal of the research on the issue of terminal illness has focused on: treatment; nursing care, palliative care; issues of euthanasia; only a few have looked into the familial relationships. In this regard, Anthony (2000) highlighted familial aspects of terminal illness explaining role, changes in life style and spousal affiliation. Furthermore such patients face difficult social circumstances and become dependent on their spouses for maintaining a healthy role in their families (Lowry \& Atcherson, 2001). It is found that many such patients shifted responsibility of their care and treatment to their partners once 
they are brought home; and only $65 \%$ of patients assisted with preparation for their own care (Brown et al, 2006). A research study performed on 40 spouses of terminal cancer patients confirmed that for their own productive life style, majority of spouses were dependent on their patients' satisfaction level (Pevalin \& Goldberg, 2003).

Studies confirmed that individual adaptation of a spouse is mostly predicted by a patient's adjustment to terminal illness and hence the marital partnership plays a major role in the care process (Horsburgh et al. 1998). Literally a very few researches can be found that have studied the dyad relationship in a single research since generally terminal patients and their spouses are focused separately. For example Lowry \& Atcherson's (2001) studied both patients and their spouses in a single research activity proving the existence of insomnia and anxiety in both patients and partners equally just after the declaration of the disease as 'terminal'. Although patients indicated nervousness of their partners they claimed their marriages to be successful and with few troubles. Another study proved that among partners 20\% of such patients face depression, sadness, anxiety and stress (King \& Crowther, 2004).

Conclusively there is significant difference in the level of depression among terminally ill patients and their spouses. However this conclusion should not be considered as ultimate because a further review of literature indicates that merely $1 / 3$ of terminally ill patients decide to participate in such studies. The current study has focused on data collection from terminally ill patients and alterations in their spousal relationships as revealed through detailed discussion.

\section{Plan of Work}

This study included the participants who were diagnosed as terminally ill at least in the last 6 months. Moreover, participants were required to be married having spouse alive. Patients with acute morbid conditions, unable to communicate and having a history of dementia were excluded. Medical facility chosen for this study was Nawaz Sharif Kidney Hospital situated in district Swat of Khyber Pakhtunkhwa. Following the inclusion criteria 36 terminally ill patients (24 male patients \& 12 female patients) were selected for interview (see table. 1).

\section{Procedure}

After approval from the Advanced Studies and Research Board (ASRB) University of Malakand, research participants were accessed in person to take part in the study. To protect the identity of the patients, interviews were conducted confidentially. Through separate interviews it was possible to do an open discussion without being influencing others or being influenced by them. Each respondent signed an informed consent before the interview. All the subjects were free to express their views regarding their illness and social relationships. The interviews were audio recorded.

Table 1 Demographic and Clinical Information of the Respondents

\begin{tabular}{|c|c|c|}
\hline $\begin{array}{l}\text { Demographic/ } \\
\text { Clinical } \\
\text { Information } \\
\end{array}$ & $\begin{array}{l}\text { Male patients } \\
(n=24)\end{array}$ & $\begin{array}{l}\text { Female patients } \\
(n=12)\end{array}$ \\
\hline $\begin{array}{l}\text { Mean age } \\
\text { (years): }\end{array}$ & 41.08 & 35.7 \\
\hline Gender: & $61.5 \%$ & $38.5 \%$ \\
\hline $\begin{array}{l}\text { Marital } \\
\text { Status: } \\
\text { Single } \\
\text { Married }\end{array}$ & $\begin{array}{l}0 \% \\
100 \%\end{array}$ & $\begin{array}{l}0 \% \\
100 \%\end{array}$ \\
\hline $\begin{array}{l}\text { Occupation: } \\
\text { Unskilled } \\
\text { Professionals } \\
\text { Housewife }\end{array}$ & $\begin{array}{l}25 \% \\
41.6 \% \\
----\end{array}$ & $\begin{array}{l}8.3 \% \\
25 \%\end{array}$ \\
\hline $\begin{array}{l}\text { Average } \\
\text { income } \\
\text { (per month): }\end{array}$ & 56000 PKR & 18000 PKR \\
\hline $\begin{array}{l}\text { Average } \\
\text { duration of } \\
\text { terminal } \\
\text { illness: }\end{array}$ & 1 year & 1 year \\
\hline
\end{tabular}

\section{Analysis and Discussion}

By using the Husserlian phenomenological approach transcripts were analyzed. The Husserlian approach uncovers a sense of human experiences through talking to people who are living with the true experience (LoBiondo-Wood \& Haber, 1994). Thus the purpose of the transcript analysis was to reveal the essential character of the lived terminal illness experiences for the patient by 'bracketing' the researcher's preconcep- 
tions. As Lubeck \& Hubert (2005) explain "The phenomenologist wants to investigate meaning conferring acts which are strictly relative to the specific place, time, circumstances, participants, culture and personal experiences of respondents". Earlier research has found that verbal samples include valid indices of the person's psychological state in psychiatric and medically unwell groups (Spector, 2000).

To obtain respondents' unprompted experiences, open-ended research questions were designed. To get a real sense out all transcripts were first read twice. After reaching a consensus by the researchers, themes were extracted in accordance with the phenomenon under consideration. To identify the actual meaning of themes some participants were interviewed again for validation of themes. Researchers made sure that results were applicable to the concerned research population.

\section{Results}

Many noteworthy statements were recognized about the impact of terminal illness on patients' social lives and their dyadic relationships. Table 2 presents examples of significant statements and their originated meanings. A female patient described that significant physical limitations are developed due to tiredness, altered temper and a loss role and authority in the family circle. Some other patients also expressed similar effects, like social limitations and fatigue.

\section{A. Patients' perspective regarding terminal illness and its impacts}

Patients' responses were analyzed and various themes extracted to highlight the impacts of terminal illness on their physical and emotional health.

\section{Theme 1: Uncertainty of health causing anxiety}

Most patients were in doubt about their health security as the minimal positive health status was interrupted by episodes of acute illnesses: I do not see any hope of a healthy life but somehow I try to recover as soon as possible. The medical staff is surprised over my living. According to them life is capricious and I do agree with them. As I visit the hospital infrequently and watch those patients who are worse off than me, I start fighting my disease again till a next acute episode attacks me. There are infrequent episodes of happiness and sorrow in my life. Now the doctors try to keep me sedated most of the time. This sedation is not helping me that much.

The relationship between fatigue and terminal illness was described by the patients in detail. This was same for them as well as their partners: This disease has weakened me a lot. I feel that my lower limbs are not parts of my body anymore. I sit and hardly stand with the help of others. My husband spent most of the day in his shop and when he comes home he has to look after me and the children for hours. This is really a big physical burden for him.

\section{Theme 2: Changes in daily life since the beginning of terminal illness}

The relative impacts of terminal illness on patients' lives were discussed by all respondents in detail. Limitations imposed by disease leading to social exclusion was a great concern for all. Due to various physical and medical needs all the

Table 2 Statements of terminal patients' experiences and their dyadic relationship

\begin{tabular}{|c|c|}
\hline Patients' Statement & Extracted Meaning \\
\hline $\begin{array}{l}\text { I It is a surprise for to be still alive.... am not } \\
\text { sure when another episode of illness will } \\
\text { strike me. } \\
\text { II I get absolutely fed up...... why the people in } \\
\text { surroundings are changed so quickly and un- } \\
\text { expectedly } \\
\text { III We are living as a couple for } 16 \text { years and we } \\
\text { have a good time. Beside minor difference of } \\
\text { opinion sometimes we enjoyed a good life to- } \\
\text { gether. This illness has made some problems. }\end{array}$ & $\begin{array}{l}\text { I Anxiety was prevalent among patients due } \\
\text { to uncertain health conditions } \\
\text { II Many unexpected psychological responses } \\
\text { were exhibited by the terminally ill patients } \\
\text { (including annoyance) } \\
\text { III Respondents portrayed positive relationship } \\
\text { with their spouses with some signs of hope- } \\
\text { lessness }\end{array}$ \\
\hline
\end{tabular}


time, most patients were unable to go outside their residence. This situation was faced by all the patients: We want to visit various venues, places and relatives but we need to carry various medical equipment and take medicines with us. This is troublesome not letting us to move freely. This illness has changed our normal life.

Some patients explained changes in earnings due to inability to perform their job. This has led to many life-style changes. Some changed their residences facing a new physical environment and neighborhood: This was our dream to live in a house owned by us, and luckily we built our own house. We were really happy there. Then I got ill. Now we are living again in a rental house near the hospital because traveling from far away is difficult for all of us. However, living near a medical facility is also an advantage.

Almost all of the patients highlighted the harmful impacts of terminal illness, for example financial changes, changes in role, and social exclusion. Among these, social isolation was a major concern as explained by patients: I used to recite the Holy Quran daily and it brings mental satisfaction to me. I do it in a separate place. I do not want to meet people frequently as I used to do it in the recent past.

\section{Theme 3: Severity of illness and negative emotional responses}

Terminal illness and related medical procedures imposed some physical, social and psychological restrictions on patients. These limitations led to some emotional responses including depression, anger and daydreaming ideas. Some patients wished to enjoy a disease free life for a week and take care of their children. Some patients refused to cope with the impact of the disease and did not consider themselves as terminally ill: My disease is not the fatal one. I have seen patients on YouTube who have undergone liver transplant successfully. I hope I will be better soon.

Many patients did not describe their disease name specifically but called it as 'it' in an angry unconcerned mood while some were living in fantasy of life without disease. This was an idealistic expectation: I will get better soon InshAllah (if Allah Wills). I have seen some patients who were severely ill and were treated get healthy. I believe in miracles.
SDome patients were angry because terminal illness affected their social and family roles i.e. from independence to dependence. Answers were full of anger and annoyance: I am truly frustrated. I was a fine wood worker. I got ill at a younger age. Now I cannot join my friends company. This has been happening for the last 10 months.

\section{B. Patients' perspective regarding terminal illness and its impacts on spousal relationships}

Following data analysis, patients' opinions regarding the effects of terminal illness on spouse relationships were organized and represented in the form of separate themes.

\section{Theme 1: Constructive aspects of patients' marital relationships}

Respondents expressed optimistic views regarding spousal relationship. Negative remarks were less common among their statements. Most patients were in their marital relationship for more than 10 years. All respondents explained the role of their spouses with respect, sympathy and appreciation. Talking about her husband an interviewee was a bit shy: We always took care of one another for the last 14 years since our marriage. Now after I got ill, my husband never let himself to be careless or bored.

Subjects also talked about the personality and nature of their spouses. According to them some were solicitous and soft-hearted, while others were too much worried for them. Some showed a friendly and cordial behavior whereas some were restless. The spousal relationship of many patients was based on intimacy and respect: Since I got ill, the only major source of my assistance is my wife because she manages those aspects of my illness which cannot be performed normally by someone else.

Patients described the role of their partners as positive and cooperative: courage, love, care and friendliness were the words used by patients during the interview. Both male and female patients praised the role of their partner.

\section{Theme 2: Thoughts of liability towards the spouse}

Some subjects expressed their feelings telling that their severity of illness has caused physical 
and psychological burdens for their partners: $\mathrm{He}$ (my husband) performs several tasks at a time like his job, caring me and also managing household activities sometimes.

Respondents also showed worry about the health of their spouses. This is due to the extra workload faced by partners during the care and treatment process. They also appreciated the partners for the provision of physical and psychological support: She (My Wife) waits for me all the time before I reach home. She calls me frequently when I am not at home. She never felt her tiredness to me but I can feel how tough her life is.

\section{Theme 3: Weary response of spouse towards patients}

Some patients explained the altered behavior of spouses and their changing attitude towards them. Their partners seemed to be overtired and ignoring them sometimes: After commencement of my illness as serious, my wife was extra carful initially. She managed both me and the children very well but with the passage of time my needs were too many to be managed. I felt that she is exhausted to manage everything all the time. I think this is normal for any human being.

Moreover the ambiguous gratitude of the spouse was explained by patients: Sometimes my husband portrays me as self-centered, demanding and impatient. This is often true when I am in pain or need an immediate help.

\section{Theme 4: Spousal relationship failure}

Many patients explained loss of physical intimacy and partnership due to terminal illness: It has badly influenced our marital relationship. We both remain too much exhausted to perform daily routines. We are busy handling the disease and related complications. It has caused physical and psychological troubles which do not let us to take care of our marital adjustments.

The expressions of patients were such that they thought their life has come to an end since the onset of terminal illness because they used past tense during the interview discussion.

\section{Discussion}

This research study focused to explore the impacts of terminal illness on patients and the dyadic relationship they have with their spouses. The results revealed a complex interrelation be- tween terminal illness and anxiety, depression, role alteration and emotional disturbances. Although the data showed a combination of both positive and negative reactions of the respondents towards their disease and health status, majority expressed depressing features of terminal condition. This is probably due to: severity of illness; co-morbidities; low socioeconomic status; disorganized healthcare systems. Alternatively it could be perceived that terminal illness is itself a negative life event. Such illness leads to negative features like: \limited social interaction; irritation; anxiety; other key variations in life-style.

During the interview process it was eminent that patients were exhausted all the time and unable to do anything and were tired. Our findings: depression; anxiety; social exclusion; insecurity regarding the future were similar in nature as found in other research by the Council on Scientific Affairs, American Medical Association (1996). Terminal illness is a combination of fatal attacks, unpredictable episodes of acute illnesses as well as stability. This complex scenario of health leads patients towards psychological and spiritual adjustments where they start believing in fate and miracles.

All the subjects expressed their views regarding the impact of terminal illness on spousal relationship. Patients expressed major life-style changes since the commencement of their illness. Some of their concerns were failure to do work, to travel and to move to another place with their spouses. Hinton (1994) also found some results which highlight similar family concerns. Some patients explained that social isolation, loneliness and prolonged treatment procedures have affected marital relationship and were their most important worries. Terminal illness and related complex treatment protocols have pushed patients to face sadness, anger, and fatigue.

Accordingly their spouses were also regularly resentful, exhausted and nervous. Unexpectedly, some patients explained their spousal connection as very constructive, lovely, and full of care. The impacts of terminal illness on marital relationships were expected to be complex, negative and uncertain due to associated co-morbidities and social detachment. However, this study found that it is not true in every case. Probable conclusion of this might be that they had a consistent marital relationship before the onset of terminal illness. 
The role of the spouse in supporting health of their partners was acknowledged by the subjects. They admitted that without help of their spouse treatment and care would impossible. However, the loss of physical intimacy, inequality in partnership and dependence were indicated as hurtful results.

Some limitations of this research were different in economic and educational status of the samples. Some mystifying effects might be due to the low socioeconomic status and not the disease. Moreover, the use of an audio recorder might have an artificial impact on the expressions of the respondents.

\section{Conclusion}

Following a phenomenological plan, this research study has described the experiences of terminally ill patients and the impacts of their disease on them and their spousal relationship. Life with terminal conditions is fearsome for both patients and their family members especially their partners. The findings show similar types of concerns for almost all the patients i.e. sadness, anger, hopelessness, etc. Similarly the marital partnership has been affected about which the respondents expressed various positive and negative consequences.

Improvement in the socioeconomic status, provision of advance medical facilities can help to minimize patient suffering. Moreover, familial socio-psychological support and positive dyad relationship can assist such patients to live with a quality life till the end. The suggestions for the sociologists and psychologists are that they need to identify and answer to the incredible psychosocial impacts that serious illnesses and related medical procedures can have on the patients and their families in a modern era of advance technology.

This research study provides a platform to the researchers to explore some other aspects of terminal illness. These may include alteration in religious spirituality, parental relationships and economic impacts.

\section{Acknowledgements}

The researchers would like to thank: Mr. Mia Syed RN, BSN and Mr. Akhtar Ali RN, BSN, (Nawaz Sharif Kidney Hospital Swat). They helped us in getting access to the field site and convincing the respondents to freely express their views in response to the interview questions.

\section{References:}

1. ALLEN M (2003) Into the mainstream Care leavers entering work, education and training. York: Joseph Rowntree Foundation.

2. ALTSCHULER J (1997) Working with chronic illness: A family approach. MacMillan, Hong Kong.

3. ANTHONY W (2000) A recovery-oriented service system: setting some system level standards, Psychiatric Rehabilitation Journal, 24(2): 159.

4. BROWN D J, CRAICK CC, DAVIES S E, JOHNSON M L, DAWBORN J K, HEALE W F (2006) Physical, emotional and social adjustments to home dialysis. Medical Journal of Australia, 1, 245-247.

5. BURTON H J, KLINE S A, LINDSAY R M, HEIDENHEIM P (2004) The relationship of depression to survival in chronic renal failure. Psychosomatic Medicine, 48, 3-4.

6. COUNCIL ON SCIENTIFIC AFFAIRS, AMERICAN MEDICAL ASSOCIATION (1996) Good care of dying patient. JAMA, 275, 474-478.

7. HINTON J (1994) Which patients with terminal cancer are admitted from home care? Palliative Medicine 8, 197-210.

8. HORSBURGH M E, HILL RICE V, MATUK L (1998) Sense of coherence and life satisfaction: Patient and spousal adaptation to home dialysis. American Nephrology Nurses Association Journal, 25, 219-228.

9. HUI D, NOORUDDIN Z, DIDWANIYA N, DEV R, CRUZ M, KIM S H, KWON J H, HUTCHINS R, LIEM C, BRUERA E (2014) Concepts and definitions for "Actively Dying, "End of Life," "Terminally Ill," "Terminal Care" and "Transition of Care": A systematic review. Journal of Pain and Symptom Management, 47 (1), 77-89.

10. KING J E, CROWTHER M R (2004) The measurement of religiosity and spirituality: Examples and issues from psychology. Journal of Organizational Change Management, 17, 83-101.

11. LEVY N B (1996) Turning points: Psychosocial issues. Dialysis and Transplantation, 25, 678-684. 
12. LOBIONDO-WOOD G, HABER J (1994) Nursing research: Methods, critical appraisal, and utilization (3rd edn). Mosby, St Louis.

13. LOWRY M R, ATCHERSON E (2001) Spouse-assistants' adjustment to home hemodialysis. Journal of Chronic Disease, 37, 293-300.

14. LUBECK D P, HUBERT H B (2005) Self-report was a viable method for obtaining health care utilization data in community-dwelling seniors. Journal of Clinical Epidemiology, 58, 286-290.

15. PEVALIN D, GOLDBERG D (2003) Social precursors to onset and recovery from episodes of common mental illness, Psychological Medicine, 33(2): 299-306.

16. SOHLMAN B (2004) A functional model of mental health as the describer of positive mental health. STAKES Research Reports 137 National Research and Development for Welfare and Health: Helsinki.

17. SPECTOR R E (2000) Cultural diversity in health and illness (5th ed.). Upper Saddle River, NJ: Prentice Hall. 